\title{
ECC
}

Eurasian Chemical Communications

\section{Improvement in gas migration reduction in oil wells by using nanoparticles: an experimental investigation}

\author{
Mahmoud Bayanaka, Soroush Zarinabadia,*, Khalil Shahbazib, Alireza \\ Azimi $^{\mathrm{a}}$ \\ a Department of Chemical Engineering, Mahshahr Branch, Islamic Azad University, Mahshahr, Iran \\ ${ }^{b}$ Petroleum Engineering Department, Ahvaz Faculty of Petroleum Engineering, Petroleum \\ University of Technology (PUT), Ahvaz, Iran
}

Received: 13 October 2019, Accepted: 02 November 2019, Published: 23 November 2019

\begin{abstract}
In recent years, improving the quality and composition of cement slurry has been one of the most important challenges for researchers and oil and gas well drilling industries. It has been demonstrated that, nanoparticles have made some progresses in the operational characteristics of the conventional cement. This research, via 13 experimental attempts, revealed a great improvement in compressive strength and rheological properties of the cement slurry after addition of silicon dioxide nanomaterial to the slurry. However, it did not make any significant change in the free water content of the cement and fluid loss. In the case of static gel strength analyzers (SGSA) test, transient time followed a decrementing pattern by increasing nanoparticle percentage. As a result, it met the vital goal in drilling industry via deep reduction in gas migration rate, solving the foregoing problem without having any negative effects on the other properties of the cement slurry such as thickening time. Moreover, the Mohr circles analysis demonstrated that, higher compressive strengths were achieved.
\end{abstract}

Keywords: Cement design; cement slurry; gas migration; rheology; nanoparticles.

\section{Introduction}

Undoubtedly, cementing is the most effective way to isolate different zones of any oil or gas well with different geological conditions. In the process of drilling a oil or gas well, the well-bore diameter may be decreased step by step. In each step, drilled segment is cased by steel pipes and these casing pipes are fixed by cementing operation that has been done behind them. It should be mentioned that separation of different formation layers with different pressures

*Corresponding author: S. Zarinabadi

Tel: +989166513309, Fax: +98 (61) 34937333

E-mail: soroushzarinabadi@iauahvaz.ac.ir and fluid contents is the most important reason for cementing [1]. While the cement slurry changes its initial properties as well as its state during the operation, adjusting the setting time of the cement depends on various factors, creating different operational conditions. Determination of cement type, its composition and volume for pumping are the key factors that should be calculated accurately prior to cementation $[2,4]$. Globally, one of the most dangerous and complex challenges in drilling industry is

Eurasian Chem. Commun., (2020) 13-26 
gas migration. It occurs in three different categories. Statistics have shown that, around $15 \%$ of primary cementing operations in the US have not been successful for this reason [3]. In addition, migration and transmission of fluids into the cement account for mixing of fluids from different layers and increasing the probability of eruption. For the first type, magnetite additives have used to control the migration occurs in the void space between the cement and casing. The second type is the void space between the cement and wellbore in the place of mud cake which may weaken the cement bonding. Fortunately, some research showed that clay anchorage additive has a good performance for controlling this phenomenon. The third one, the most complicated type, which happens in the cement bulk due to changes in pressure during the setting process can be controlled by adding an appropriate amount of elastomer [5]. Gas migration may be controlled via some important factors that can characterize slurry properties including: density, rheology, homogeneity, fluid loss, free water, setting time profile, compressive strength, permeability, gel strength, etc. $[6,22]$. Here, mud circulation, fluid and slurry density, cement gel strength, fluid loss, free water, cement permeability, micro annuluses and applied pressure in annulus are the key factors managing this complex phenomenon [6,19] while petroleum industry has this problem since the early 60 's $[7,24]$. In the early of 1960 's, the importance of the surface of the pipes, roughness and wettability, in the proper connection between cementcasing and cement-formation was revealed $[8,9,21]$. On the other hand, Wenger et al. (1965) introduced a special mechanical device with the ability to connect to the casing in order to control the relevancy between the layers [10]. Stone and Christina developed a laboratory scale model demonstrating the fact that if the cement hydrostatic pressure after initial setting time was less than the gas pressure, the gas migration phenomenon will continue. Moreover it was suggested that, in addition to the proper slurry properties, cementing operation and mud removal are effective in this field of study [11] as well as quality of cementing [12]. In 1977 an upgraded method was suggested that during cementing of high pressure zones, the maximum possible value of controller additives should be used to minimize the gas leakage [13]. Another way for optimizing the gas migration is using the expanding cements for better bonding of cement in the contact area of cement-casing and cement-formation. An essay that comprehensively addressed this issue was published by Griffin et al. (1979). In this work, an special system of expanded cement was used to provide an ideal condition for cement bonding [14]. Also, the fundamental factors were evaluated and studied for their effects on cementing that summarized as heat, pressure, slurry weight, particle size and finally volume fraction of spices [25]. Goboncan and Dillenbeck (2003) evaluated the cementshrinkage and proposed that in theoretical side of view, shrinkage happened with two states of overall shrinkage and porosity in cement matrix [26]. Also Mata et al. (2006) presented that usage of low density cements based on the hollow glass spheres, can weakened probability of gas migration in weak formations [27]. Bachu (2017) examined the amount of gas migration, especially greenhouse gases, outside of the casings in Canada. As a result of investigating of all data collected from conventional and thermal wells, he concluded that most of the exhausted gases are from the upper zone of the formation [15]. Al-Yami and Al- 
Humaidi (2016) could greatly reduce the amount of gas migration behind the casing with the invention of a cement mixture containing silica particles and hematite[16]. Also in 2015 they could solve a lot of problems faced with drilling of deep wells by designing special cement that performed well at high pressures and temperatures [17]. Mohammad Pour and Moghadasi (2007) pointed out that inappropriate control of fluid flow in the South Pars field in Iran has caused the problems of gas migration [18]. Their research study presented an experimental research that clarified the most influential and effective approach for introducing a special cement to prevent gas migration. Even if the above research has considered the gas migration problem, and some recommendations have been proposed, the effectiveness of sealing still needs further research. Therefore, in this work the effect of nano-silica on the cement properties and gas migration were investigated.

\section{Experiments}

\section{Material}

Nano-silica $\left(\mathrm{SiO}_{2}, 99 \%\right.$ purity, 50-60 nm in diameter), from "Nano Shell" Company (USA) was prepared, class $\mathrm{G}$ cement (API standard, from Delijan company, Iran) and conventional drilling cement additives with their trade name include O-light weight, boric acid, OUni FLC5, JR 120, JD220, O-Gas Block,TA-47, Cenosphere, J -FLC320, O-R5, O-micro block (all with the purity of $98 \%$ ). The density, BHST1 and BHCT2 of the two slurries are presented in Table 1. Also, Tables 2 and 3 summarize more details about the aforementioned cement slurries.

Table 1. Cements' slurry information

\begin{tabular}{|c|c|c|c|c|c|c|c|}
\hline Slurry & \multicolumn{2}{|c|}{ Density (lb/ft3) } & \multicolumn{2}{|l|}{ BHST $\left({ }_{0} F\right)$} & BHCT $\left({ }_{0} F\right)$ & \multicolumn{2}{|c|}{ Pressure (psi) } \\
\hline 1 & \multicolumn{2}{|c|}{88} & 205 & \multicolumn{2}{|r|}{154} & \multicolumn{2}{|c|}{5700} \\
\hline 2 & \multicolumn{2}{|c|}{92} & 205 & \multicolumn{2}{|r|}{152} & \multicolumn{2}{|c|}{5500} \\
\hline \multicolumn{8}{|c|}{ Table 2. Designed slurries with density of $88 \mathrm{PCF}$} \\
\hline \multirow{2}{*}{\multicolumn{2}{|c|}{ Additives }} & \multicolumn{6}{|c|}{ Program } \\
\hline & & $1-1$ & $1-2$ & $1-3$ & $1-4$ & $1-5$ & $1-6$ \\
\hline \multicolumn{2}{|c|}{ G Delijan (gr) } & 422 & 422 & 422 & 422 & 422 & 422 \\
\hline \multicolumn{2}{|c|}{ Water (gr) } & 267 & 267 & 267 & 267 & 267 & 267 \\
\hline \multicolumn{2}{|c|}{ O-light weight (gr) } & 135 & 135 & 135 & 135 & 135 & 135 \\
\hline \multicolumn{2}{|c|}{ Boric Acid (gr) } & 0.42 & 0.42 & 0.42 & 0.42 & 0.42 & 0.42 \\
\hline \multicolumn{2}{|c|}{ O-Uni FLC5 (gr) } & 2.11 & 2.11 & 2.11 & 2.11 & 2.11 & 2.11 \\
\hline \multicolumn{2}{|c|}{ JR 120 (gr) } & 0.13 & 0.13 & 0.13 & 0.13 & 0.13 & 0.13 \\
\hline \multicolumn{2}{|c|}{ JD 220 (gr) } & 0.63 & 0.63 & 0.63 & 0.945 & 1.26 & 0.63 \\
\hline \multicolumn{2}{|c|}{ O- Gas Block (gr) } & 18 & 18 & 18 & 18 & 18 & 18 \\
\hline \multicolumn{2}{|c|}{ TA-47 (gr) } & 0.48 & 0.48 & 0.48 & 0.48 & 0.48 & 0.48 \\
\hline \multicolumn{2}{|c|}{ Nano silica (gr) } & 0 & 1.266 & 2.11 & 2.11 & 2.11 & 4.22 \\
\hline
\end{tabular}

Table 3. Designed slurries with density of 92 PCF

\begin{tabular}{cccccccc}
\hline Additives & \multicolumn{7}{c}{ Program } \\
\hline & $2-1$ & $2-2$ & $2-3$ & $2-4$ & $2-5$ & $2-6$ & $2-7$ \\
G Delijan (gr) & 462 & 462 & 462 & 462 & 462 & 462 & 462 \\
Water (gr) & 285 & 285 & 285 & 285 & 285 & 285 & 285 \\
Cenosphere (gr) & 111 & 111 & 111 & 111 & 111 & 111 & 111 \\
J -FLC320 (gr) & 3 & 3 & 3 & 3 & 3 & 3 & 3 \\
O-R5 (gr) & 0.37 & 0.37 & 0.37 & 0.37 & 0.37 & 0.37 & 0.37 \\
JD 220 (gr) & 0.93 & 0.93 & 0.93 & 0.93 & 0.93 & 0.93 & 0.93 \\
O-micro block (gr) & 12 & 12 & 12 & 12 & 12 & 12 & 12 \\
O- Gas Block (gr) & 9 & 9 & - & 9 & - & - & 9
\end{tabular}

${ }^{1}$ Bottom Hole Static Temperature

${ }^{2}$ Bottom Hole Circulating Temperature 


\begin{tabular}{cccccccc}
\hline & & & & & & & \\
TA-47 (gr) & 0.52 & 0.52 & 0.52 & 0.52 & 0.52 & 0.52 & 0.52 \\
Nano silica (gr) & 0 & 1.386 & 1.386 & 2.31 & 2.31 & 0 & 4.62 \\
\hline
\end{tabular}

\section{Experimental procedure}

The process of testing started with an initial designing of slurry formula. All the tests were performed according to the proposed programs as depicted in the above Tables 1-3. The considered slurry was used in a "7 inch" liner where gas migration was reported after its setting. This cement slurry was retested as the base fluid and all the other samples were prepared by adding different amount of nanoparticle as showed in Table 2 and Table 3 . At the beginning, 1, 2 and $5 \%$ of nanoparticle were used while there was not any optimization for slurry cement. However, difficulties as ultimate thickening, separation and early gelation occurred and because of operational limitations complimentary tests did not performed, unfortunately. This negative effect also was seen for low values of nanoparticle that is around $0.1 \%$ wt. In this field of research if desirable conditions did not satisfy operational conditions, remaining experiments should be carried out on the new optimized slurry cement. Therefore, as a final step, FMA3 and tri-axial attempts were conducted for adequacy of results [19-21].

\section{Diagnostic tests}

The two slurries which are formulated and prepared based on the above aforementioned details should be tested and evaluated for their performance during cementing. So in the case of the rheology test, they were prepared and weighted. Thereafter, rheology tests were performed for the two types of slurries (Table 2 and 3), and then the PV and YP were calculated using the Equation 1 and 2.

$$
\mathrm{PV}=(\theta 300-\theta 100) \times 1.5
$$

$$
\mathrm{YP}=0300-\mathrm{PV}
$$

Free water in slurry cement was defined as the water which exists more than needed for the hydration of cement and additives. In this test, the slurry was poured into a $250 \mathrm{~mL}$ cylinder and kept immobile for $2 \mathrm{~h}$. Then, the amount of water collected at the top of the slurry was measured. Understudy cement slurries were processed based on the API standard for evaluation of their fluid content [22]. Fluid loss describes water or fluid content that is separated from the slurry during $30 \mathrm{~min}$ of residence time at pressure of 100 psi and ambient temperature. In thickening time measurement test, the presence of Cenospher should be considered as the specification of this substance is such that after a period of time, it may lose its resistance properties against high pressure. Cement compressive strength is the capacity of cement to withstand the loads tending to reduce the size. Testing the strength of standard cement cubes only provides information about the cured strength. To accurately and effectively schedule a cementing job with a minimum WOC time, how slurry develops strength over time during curing needs to be determined. The cement slurry was poured into ultrasonic cement analyzer (UCA) for nondestructive test in $24 \mathrm{~h}$ [23]. In a nondestructive test, sonic speed was measured through the cement as it sets. This value was then converted into compressive strength. The UCA cell was equipped with a heating jacket, temperature controller, pressure system, cooling system, and transducers and rated at $204{ }^{\circ} \mathrm{C}$ and 30,000 psi. The system measured the strength development by measuring the speed of

${ }^{3}$ Fluid Migration Analyzer 
the ultrasonic signals being sent through the cement while it sets up. The speed of the signals was calculated and correlated to a compressive strength in psi. Setiati (2017) have explained that adding nanosilica to cement slurry results in increasing of compressive strength and density, and improving mechanical properties, especially at low temperature [24]. It has been observed that, with increasing the weight percent of the nano-silica, the compressive strength of the cement may increase. However, if the proportion of nano-silica in the cement slurry exceeds some certain amount, there can be a decrease in the compressive strength of cement. In addition, as the last part of the attempt, to evaluate the performance of the cement slurry in the problem of gas migration, it is necessary to measure the gel strength development profile. For this purpose, the SGSA device was used. Static gel strength of well cement can be measured with a static gel strength measurement device (SGSM). The SGSM attaches to a standard ultrasonic cement analyzer (UCA). It uses a vanned bob to condition the cement slurry inside the UCA cell. During the test, the bob was intermittently rotating, measuring the resistance from the slurry. At the end of the test, the software provided a complete picture of the gel strength development of the cement slurry over time. As in the UCA test, the slurry was poured into the cell and after $24 \mathrm{~h}$, the result was reported as graphs [25].

\section{Results and discussion}

Rheology, thickening time, free water and fluid loss test results

In slurry preparation, adding nanoparticles to the slurry samples led to formation of different mixtures with various properties. By discarding nanoadditives percentage with more than 1 and less than $0.2 \%$, nanoparticle percentage began to increase from the lowest concentration (0.3\%wt.) to $0.5 \%$ wt. and finally, $1 \%$ wt. about the slurry with density of $88 \mathrm{PCF}$, at the presence of $0.5 \%$ wt. nanoparticles, early gelation happened. So it was decided to increase the amount of dispersant and the results were repeated. But in the percentage of $1 \%$ wt., the slurry was quickly turned to gel and became rigid. Consequently, there was no ability to increase the dispersant. For this reason, program 1-3 and 1-6 failed. About the slurry with density of $92 \mathrm{PCF}$. The presence of $1 \% \mathrm{wt}$ nanoparticles made the slurry rigid. So, the program 2-7 failed and was removed from the test list. In this section, results from rheology, free water, fluid loss and thickening time tests are presented in Tables 4 and 5 . Rheology character of slurry cement followed a positive manner at presence of nanoparticles in all types of cements. In contrast, fluid loss, free water and finally thickening time as the other three important factors for cement performance evaluations did not represented any significant change after addition of nanoparticles [26-28].

Table 4. Rheology, thickening time, free water and fluid loss test results for slurry with density of 88 PCF

\begin{tabular}{|c|c|c|c|c|c|c|c|c|}
\hline \multirow[b]{2}{*}{$\begin{array}{l}\text { Test } \\
\text { list }\end{array}$} & \multicolumn{4}{|c|}{ Rheology } & \multirow{2}{*}{$\begin{array}{c}\text { Free } \\
\text { Water } \\
(\mathrm{mL})\end{array}$} & \multirow{2}{*}{$\begin{array}{l}\text { Fluid } \\
\text { Loss } \\
(\mathbf{m L})\end{array}$} & \multicolumn{2}{|c|}{ Thickening Time } \\
\hline & $\begin{array}{l}\text { YP @ } \\
154^{\circ} \mathrm{F}\end{array}$ & $\begin{array}{l}\text { PV @ } \\
154^{\circ} \mathrm{F}\end{array}$ & $\begin{array}{l}\text { YP @ } \\
77{ }^{\circ} \mathrm{F}\end{array}$ & $\begin{array}{l}\mathrm{PV} @ \\
77^{\circ} \mathrm{F}\end{array}$ & & & $\begin{array}{c}40 \mathrm{BC} \\
(\mathrm{hr})\end{array}$ & $\begin{array}{c}70 \mathrm{BC} \\
(\mathrm{hr})\end{array}$ \\
\hline $1-1$ & 196.5 & 18.5 & 195 & 15 & 0 & 64 & 4.49 & 4.53 \\
\hline $1-2$ & - & - & 2025 & 57.5 & 0 & 64 & 4.49 & 4.53 \\
\hline $1-4$ & - & - & 772.5 & 27.5 & 0 & 64 & 4.49 & 4.53 \\
\hline $1-5$ & 240 & 30 & 750 & 60 & 0 & 64 & 4.49 & 4.53 \\
\hline
\end{tabular}


Table 5. Rheology, thickening time, free water and fluid loss test results for slurry with density of 92

\begin{tabular}{|c|c|c|c|c|c|c|c|c|}
\hline \multicolumn{9}{|c|}{ PCF } \\
\hline \multirow[b]{2}{*}{$\begin{array}{l}\text { Test } \\
\text { list }\end{array}$} & \multicolumn{4}{|c|}{ Rheology } & \multirow{2}{*}{$\begin{array}{c}\text { Free } \\
\text { Water } \\
(\mathrm{mL})\end{array}$} & \multirow{2}{*}{$\begin{array}{l}\text { Fluid } \\
\text { Loss } \\
(\mathrm{mL})\end{array}$} & \multicolumn{2}{|c|}{ Thickening Time } \\
\hline & $\begin{array}{c}\text { PV@ } 977 \\
{ }^{\circ} \mathrm{F}\end{array}$ & $\begin{array}{l}\text { YP @ } \\
77^{\circ} \mathrm{F}\end{array}$ & $\begin{array}{l}\text { PV @ } \\
152{ }^{\circ} \mathrm{F}\end{array}$ & $\begin{array}{l}\text { YP @ } \\
152{ }^{\circ} \mathrm{F}\end{array}$ & & & $\begin{array}{c}40 \mathrm{BC} \\
\text { (h) }\end{array}$ & $\begin{array}{c}70 \mathrm{BC} \\
\text { (h) }\end{array}$ \\
\hline $2-1$ & 117 & 7 & 145.5 & 16.5 & 0 & 52 & 4.5 & 4.53 \\
\hline $2-2$ & 165 & 20 & 133.5 & 14.5 & 0 & 52 & 4.5 & 4.53 \\
\hline $2-3$ & 97.5 & 6.5 & 79.5 & 10.5 & 0 & 52 & 4.5 & 4.53 \\
\hline $2-4$ & 136.5 & 21.5 & 150 & 8 & 0 & 52 & 4.5 & 4.53 \\
\hline $2-5$ & 91.5 & 6.5 & 150 & 8 & 0 & 52 & 4.5 & 4.53 \\
\hline $2-6$ & 87 & 1 & 67.5 & 6.5 & 0 & 52 & 4.5 & 4.53 \\
\hline
\end{tabular}

\section{UCA and SGSA tests results}

The results of the UCA and SGSA tests are presented in Figures 1 to 8 . Regarding the diagrams and data for the cement slurry of density $88 \mathrm{PCF}$, there is a slight decrease in the compressive strength which could be from experimental error as shown in Figures 1 and 2 .

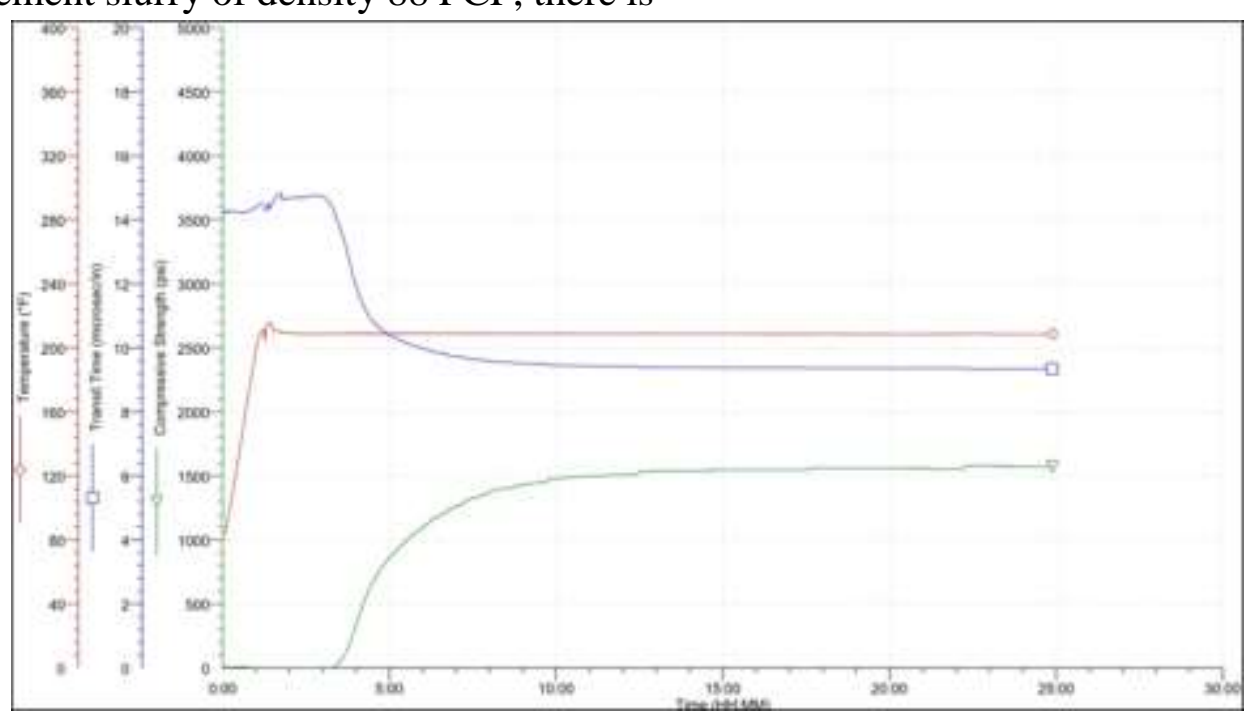

Figure 1. UCA plot for conventional slurry cement with density of 88 PCF (Prog. 1-1)

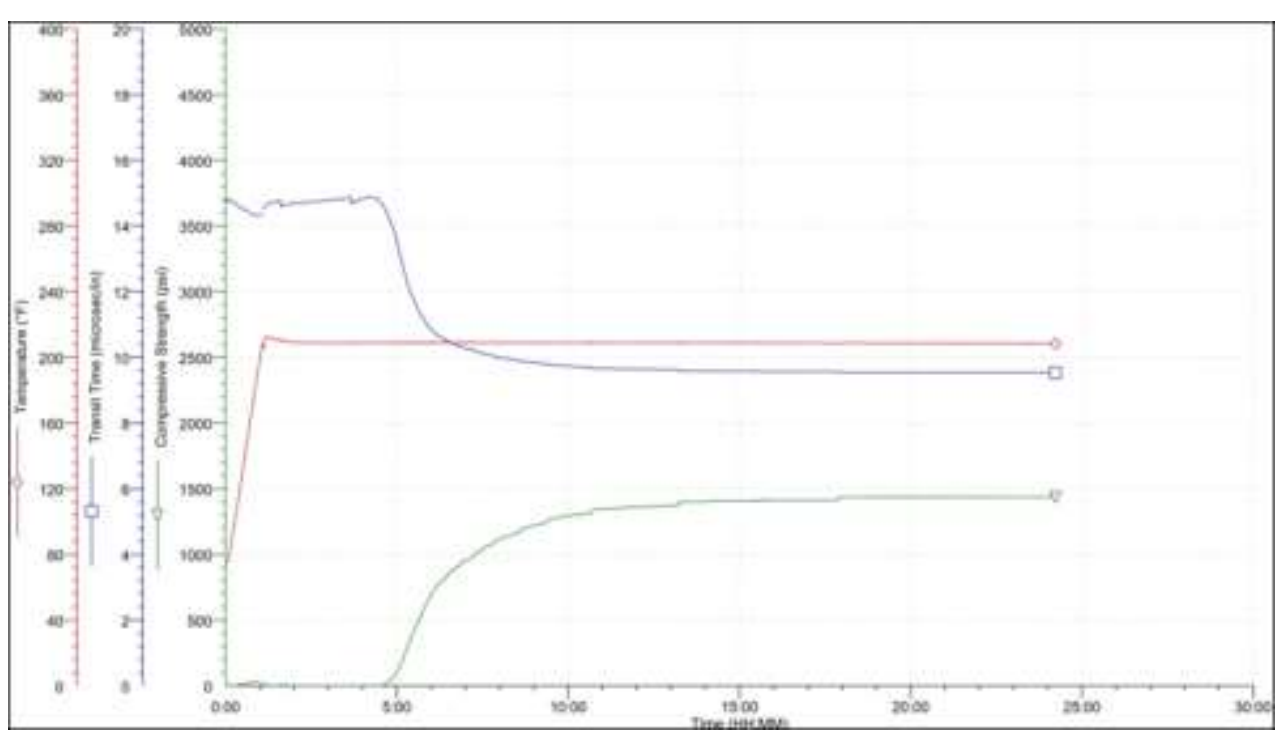


Figure 2. UCA plot for conventional slurry cement with density of 88 PCF with $0.3 \%$ wt. of nanoparticle (Prog. 1-2)

In contrary, the cement slurry of density 92 PCF compressive strength had an ascending trend in all cases which definitely demonstrated that introducing of nanoparticles has positive effect on cement structural properties as shown in Figures 3 and 4 and also in Tables 6 and 7 [29].

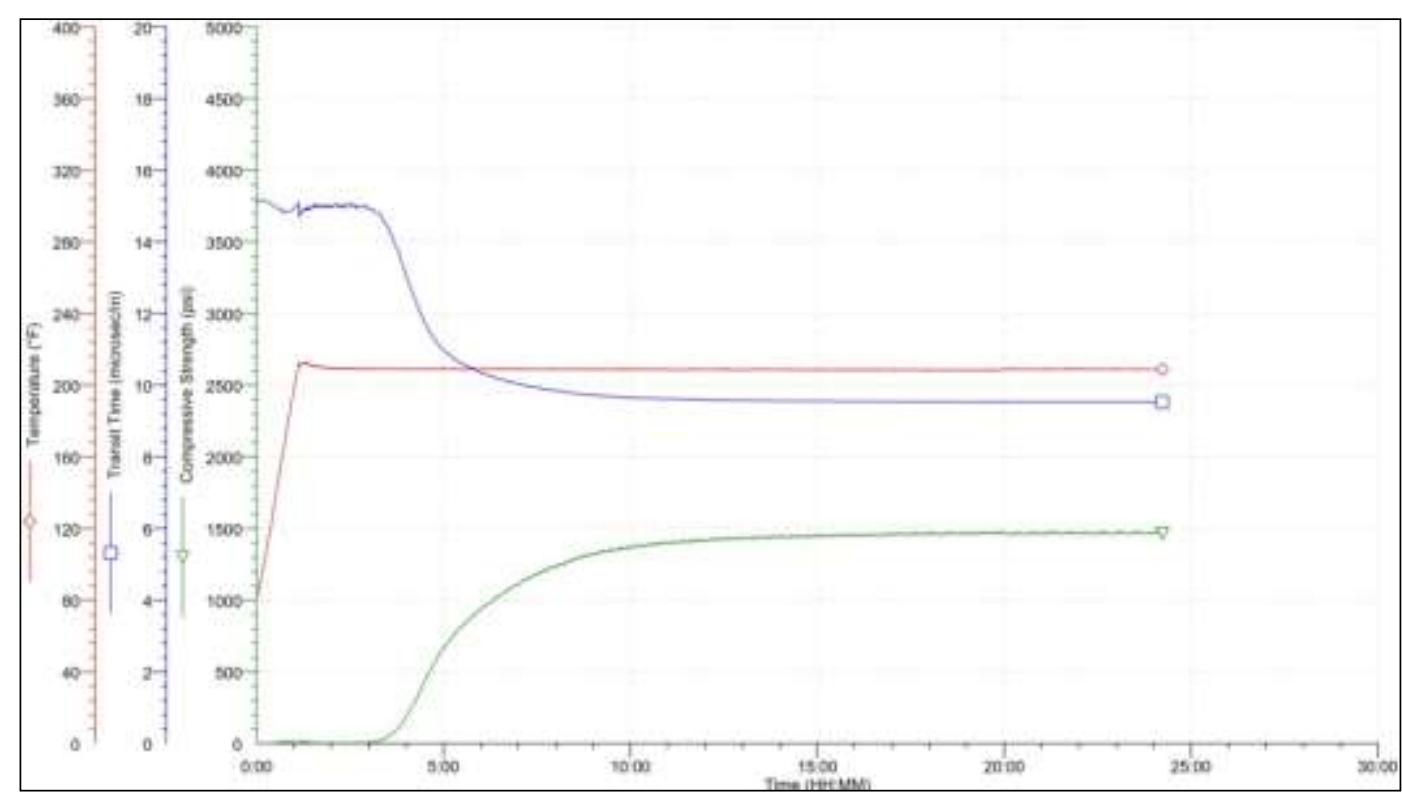

Figure 3. UCA plot for conventional slurry cement with density of 92 PCF (Prog. 2-1)

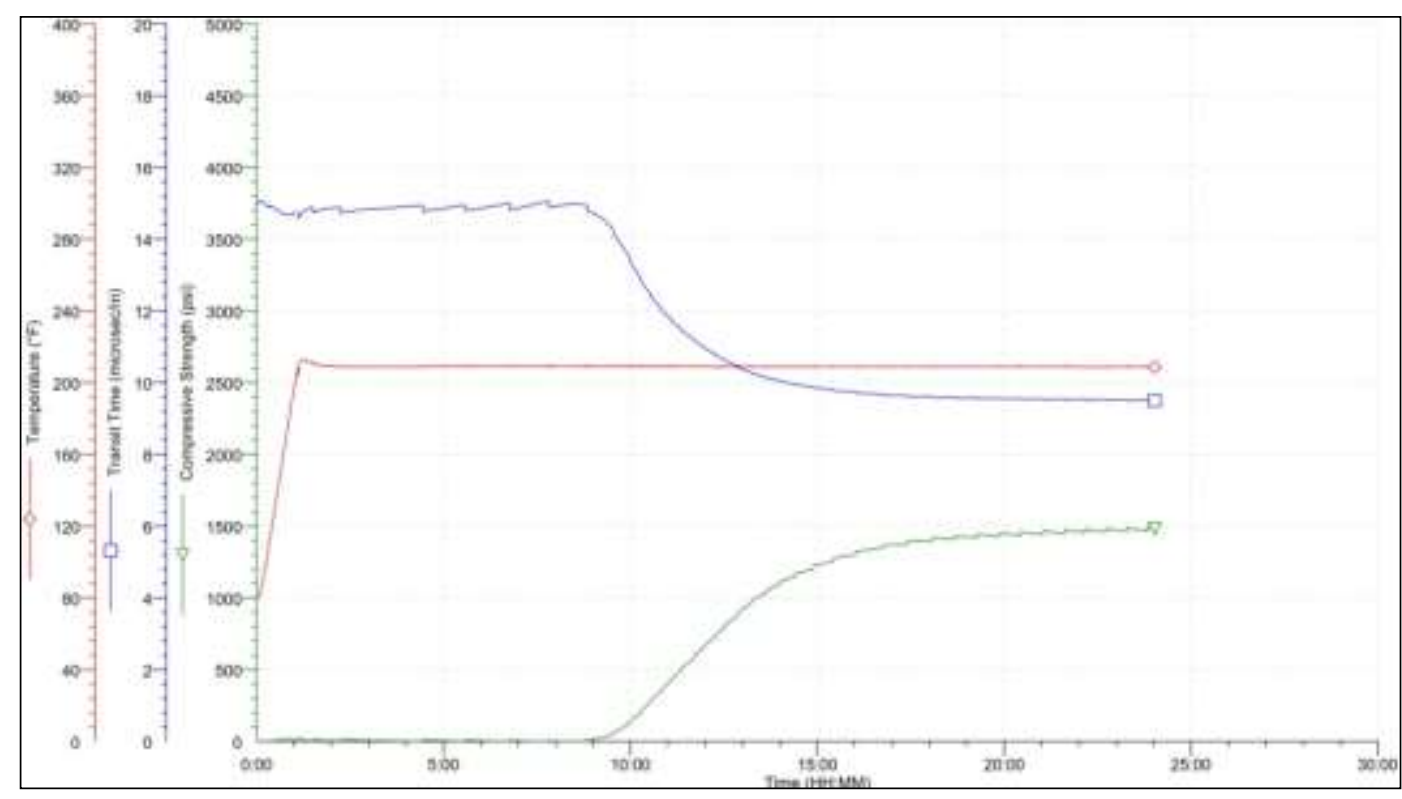

Figure 4. UCA plot for conventional slurry cement with density of $92 \mathrm{PCF}$ with $0.3 \%$ wt. of nanoparticle (Prog. 2-2) 
The SGSA tests revealed that, the transient time was decreased by feeding more amounts of nano-particles as depicted in Figures 5-8 (also Tables 6 and 7). While this property has a direct relation with cement strength, within the mentioned range the more nanoparticles fed to the cement, the more positive effects may observe on gel strength [30].

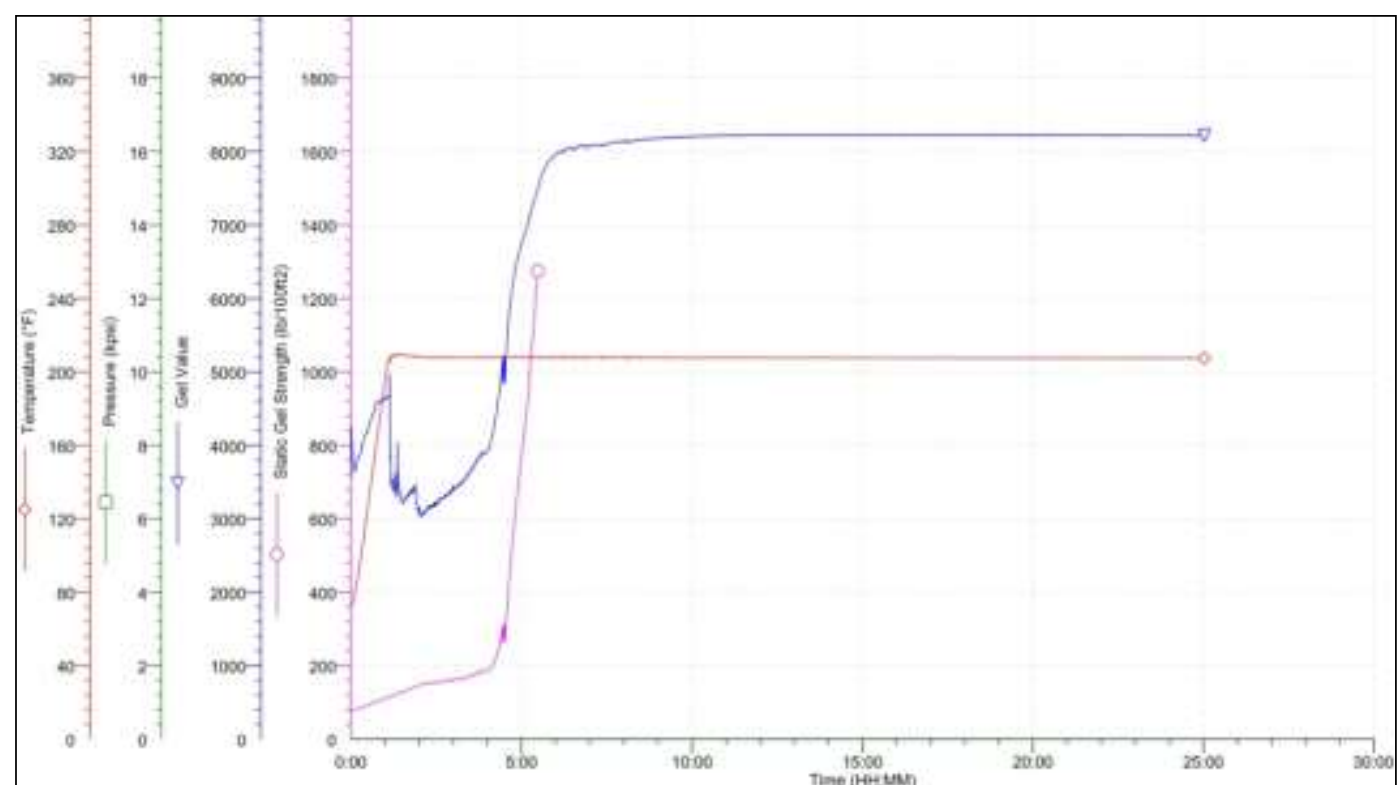

Figure 5. SGSA plot for slurry cement with density of 88 PCF and 0.3\%wt. of nanoparticle (Prog. 1-2)

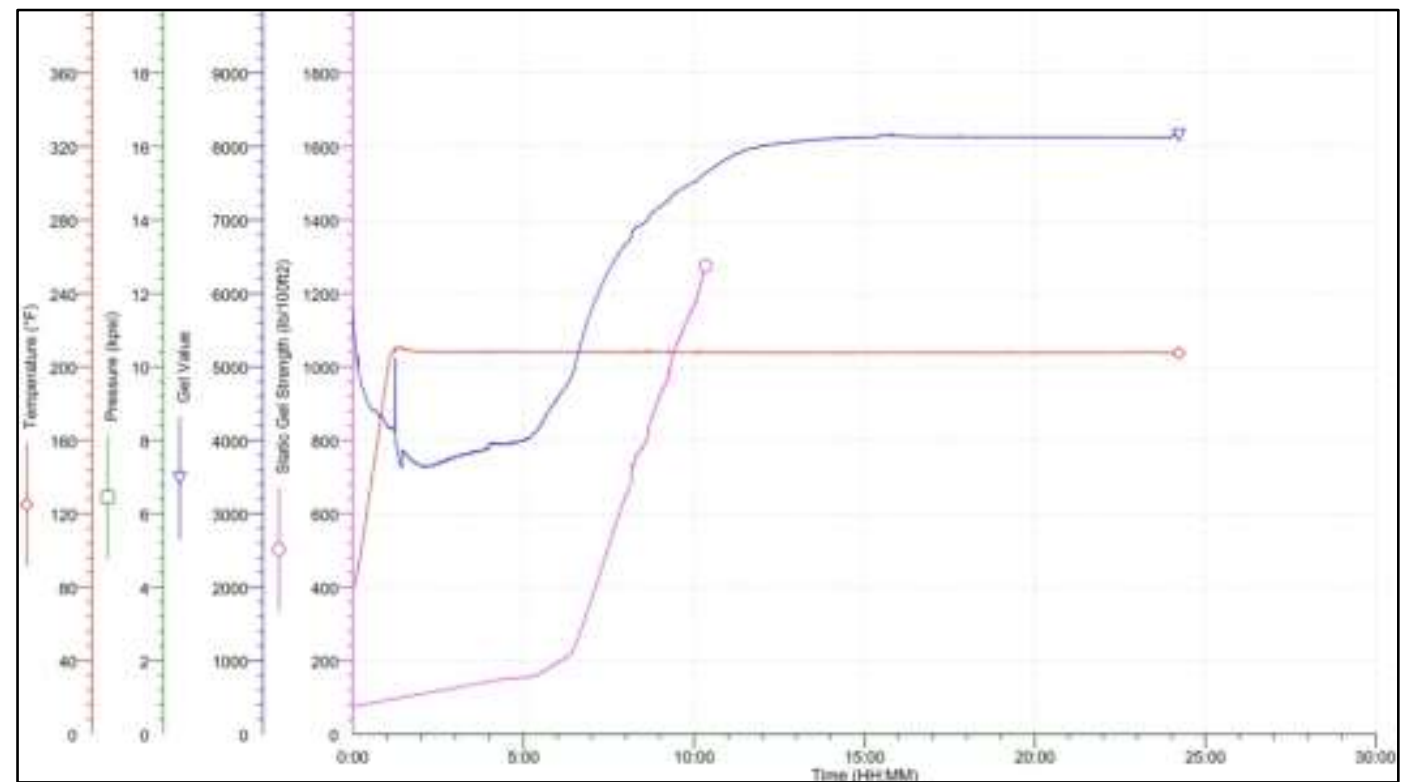

Figure 6. SGSA plot for slurry cement with density of 92 PCF and 0.3\%wt. of nanoparticle (Prog. 2-2) 


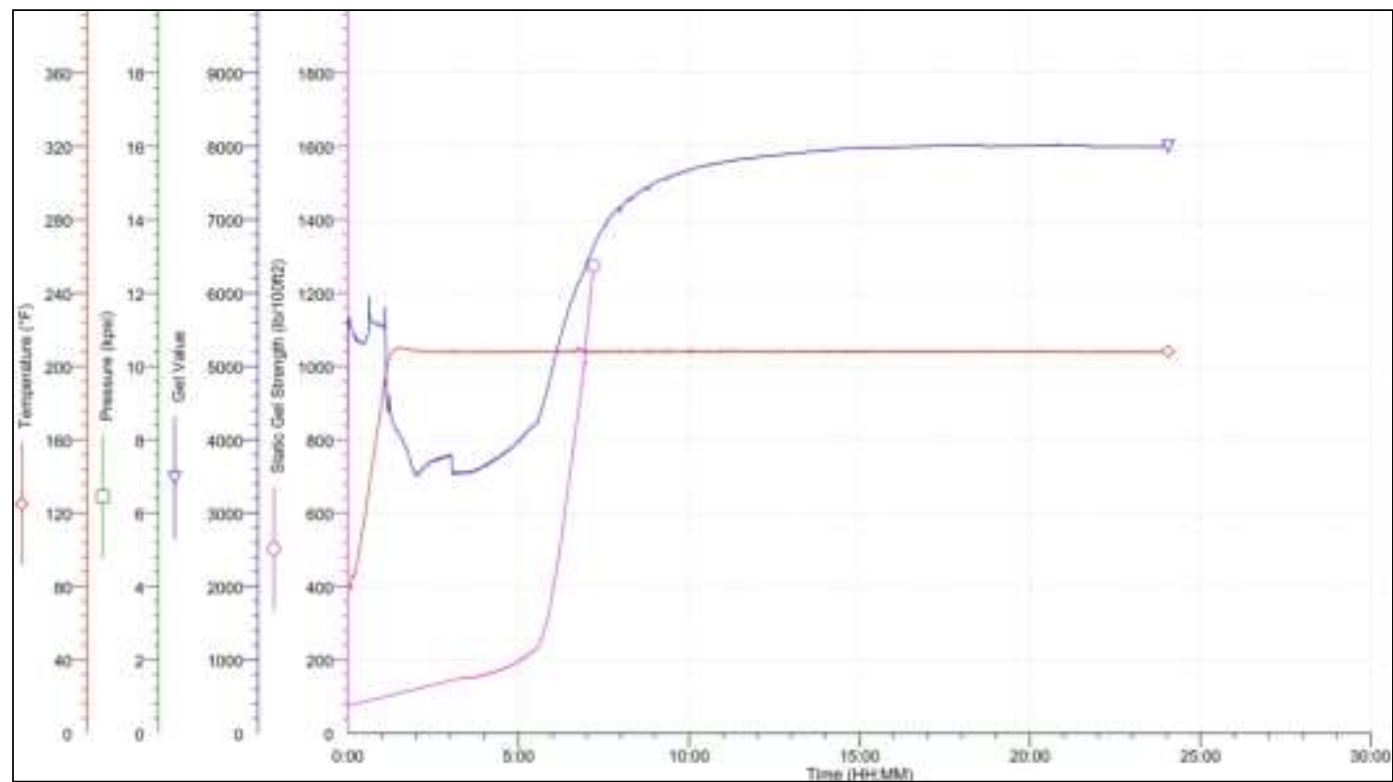

Figure 7. SGSA plot for slurry cement with density of 92 PCF without nanoparticle (Prog. 2-1)

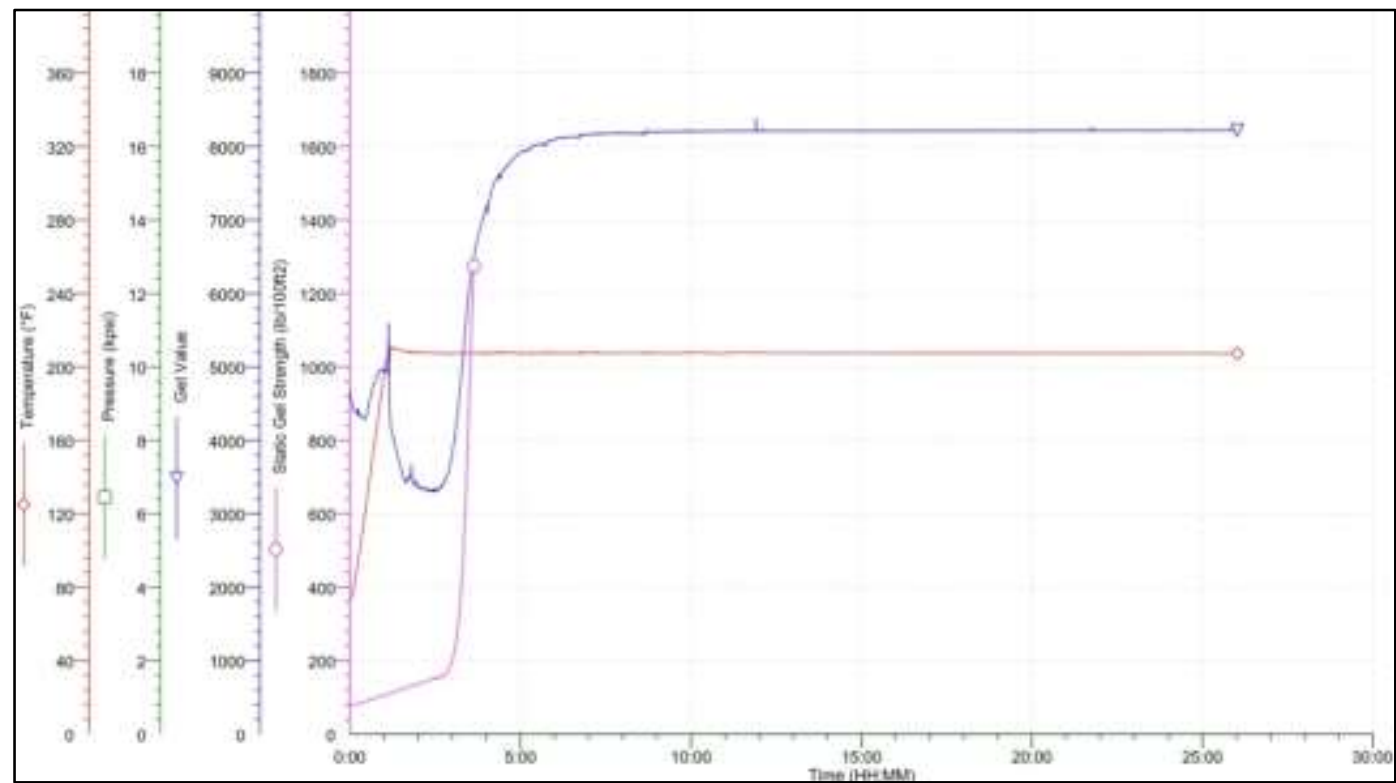

Figure 8. SGSA plot for slurry cement with density of 88 PCF without nanoparticle (Prog. 1-1)

Table 6. UCA and SGSA test results for cement slurry of 88 PCF density

\begin{tabular}{cccc}
\hline \multirow{2}{*}{ Program } & \multirow{2}{*}{ UCA (PSI) } & \multicolumn{2}{c}{ SGSA } \\
\cline { 3 - 4 } & & Transient Time (min) & $(\mathbf{l b} / \mathbf{1 0 0} \mathbf{f t} 2)$ \\
\hline $1-1$ & 1572 & 14 & 1280 \\
$1-2$ & 1436 & 10 & 1280 \\
$1-4$ & 1390 & 5.30 & 1280 \\
$1-5$ & 1355 & 5.30 & 1280 \\
\hline
\end{tabular}


Table 7. UCA and SGSA tests results for slurry cement of 92 PCF density

\begin{tabular}{cccc}
\hline \multirow{2}{*}{ Program } & \multirow{2}{*}{ UCA(PSI) } & \multicolumn{2}{c}{ SGSA } \\
\cline { 3 - 4 } & & Transient time(min) & $(\mathbf{l b} / \mathbf{1 0 0} \mathbf{f t} 2)$ \\
\hline $2-1$ & 1465 & 19 & 1280 \\
$2-2$ & 1483 & 9 & 1280 \\
$2-3$ & 1147 & $<15$ & 1280 \\
$2-4$ & 1297 & 11 & 1280 \\
$2-5$ & 1556 & 11 & 1280 \\
$2-6$ & 1823 & $<15$ & 1280 \\
\hline
\end{tabular}

Gas migration test by FMA

As it is clearly demonstrated gas migration can be measured via FMA test. So, focus on the results of this analyzing method was one of the aims in this work. Due to time and cost considerations, two types of slurries in any category were selected and analyzed (Figures 9-12). The results demonstrated that, the nanoparticles had a great positive effect on the cement slurries, prevented the gas from migration (Table 8) [31].

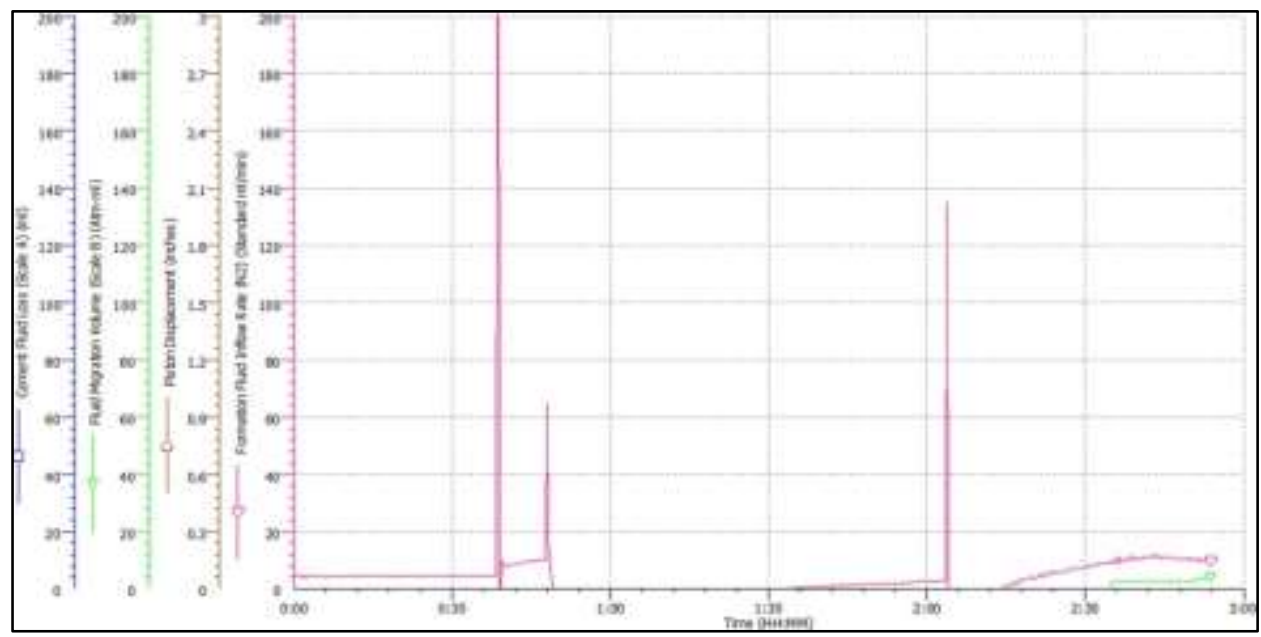

Figure 9. Gas migration plot for conventional slurry with density of 88 PCF (Prog. 1-1)

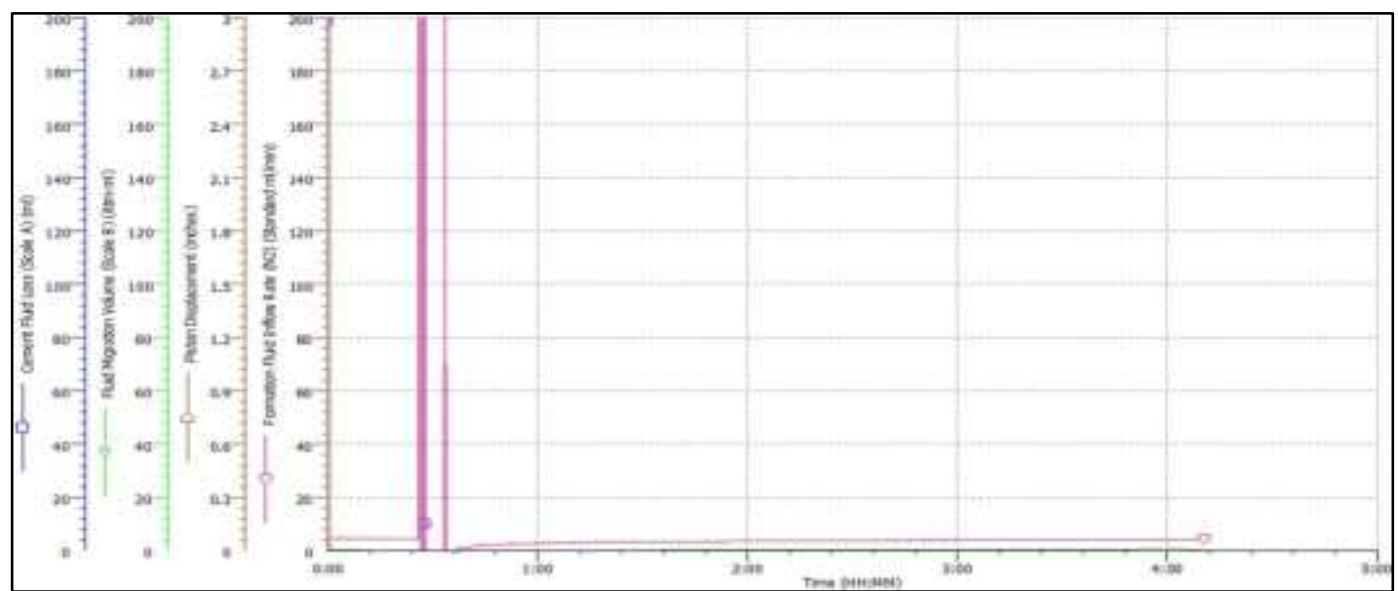

Figure 10. Gas migration plot for slurry with density of $88 \mathrm{PCF}$ and $0.3 \%$ wt. nanoparticles (Prog. 1-2) 


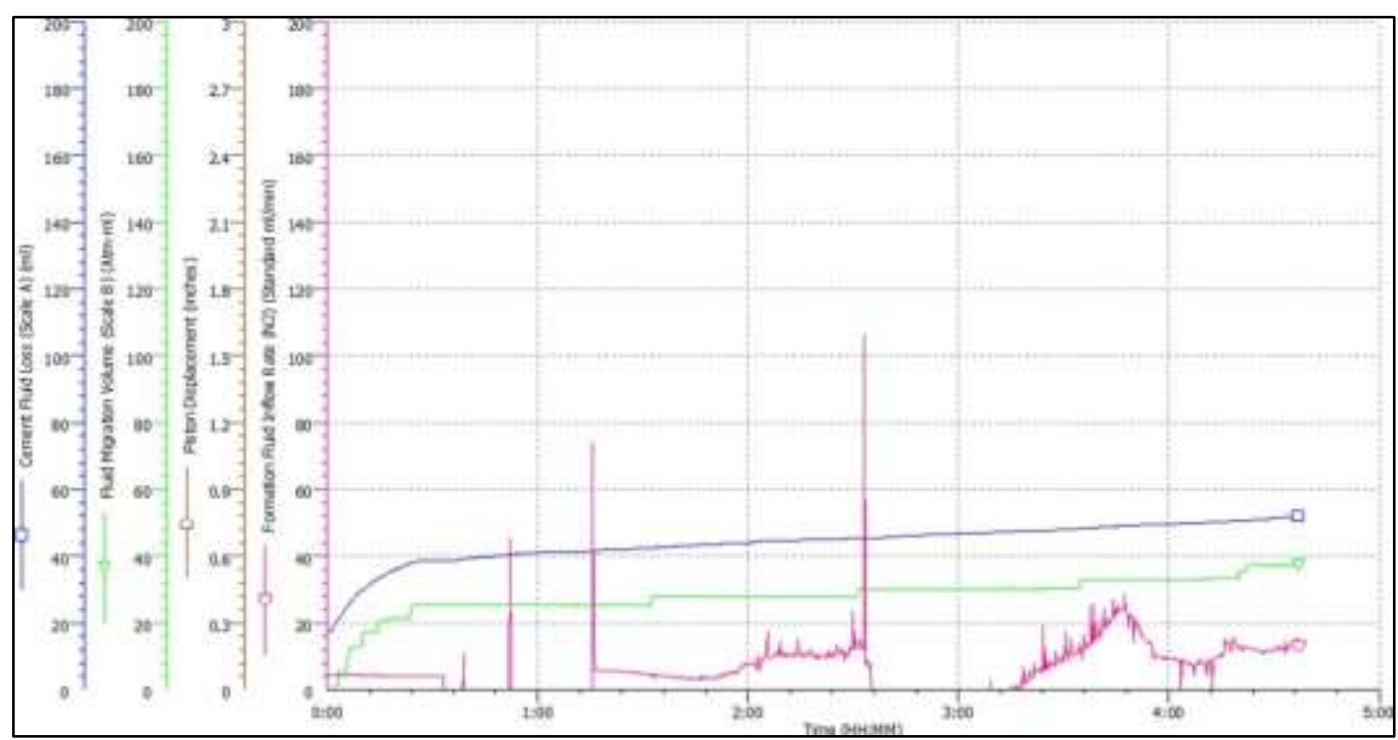

Figure 11. Gas migration plot for conventional slurry with density of 92 PCF (Prog. 2-1)

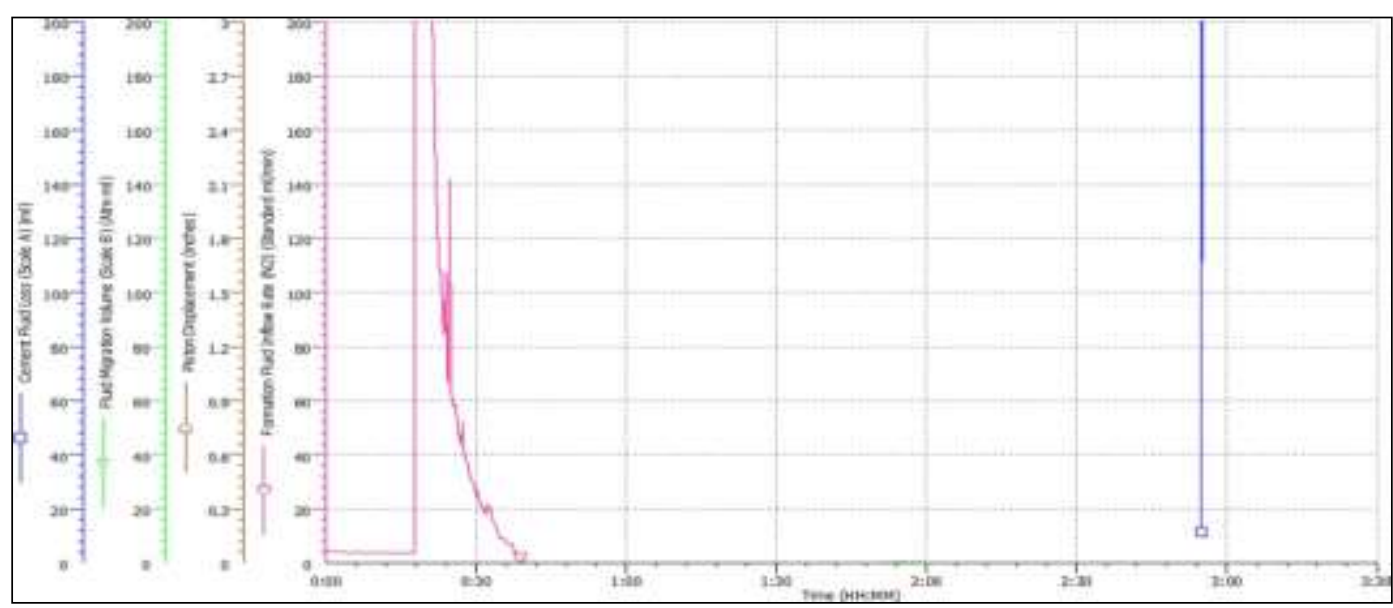

Figure 12. Gas migration plot for slurry with density of $92 \mathrm{PCF}$ and $0.3 \%$ wt. nanoparticles (Prog. 2-2)

Table 8. Gas migration test results

\begin{tabular}{lccc}
\hline \multirow{2}{*}{ 88 PCF } & Program & $1-1$ & $1-2$ \\
& Gas Migration $(\mathrm{ml} / \mathrm{min})$ & 4 & 0 \\
\multirow{2}{*}{ 92 PCF } & Program & $2-1$ & $2-2$ \\
& Gas Migration $(\mathrm{ml} / \mathrm{min})$ & 40 & 0 \\
\hline
\end{tabular}

Tri-axial tests

To compare the slurry strength before and after adding nanoparticles, Mohr's circles were plotted for cement slurry with density of 92 PCF (program 2-2 and 2-3) (Figures 13 and 14). In addition, applying these analyzing criteria provided evaluation of two important mechanical factors that is cohesion parameter (C) and friction angle $(\varphi)$ which are presented in Table 9. Based on the results, removal of anti-gas migration additive provided great situation for incrementing of failure stress (peak stress) which can be explained via enhancement the effect of nanoparticles in the absence of anti-gas migration additive. In addition, cohesion parameter in program 2-3 is much higher than that of program 2-2. This achievement shows 
the adhesion of the grains and, thus, the strength of the cement slurry. So, it can be concluded that nanoparticles not only did not reduce strength capacity of the slurry, but also improved this important property especially in the absence of anti-gas migration additive [32].

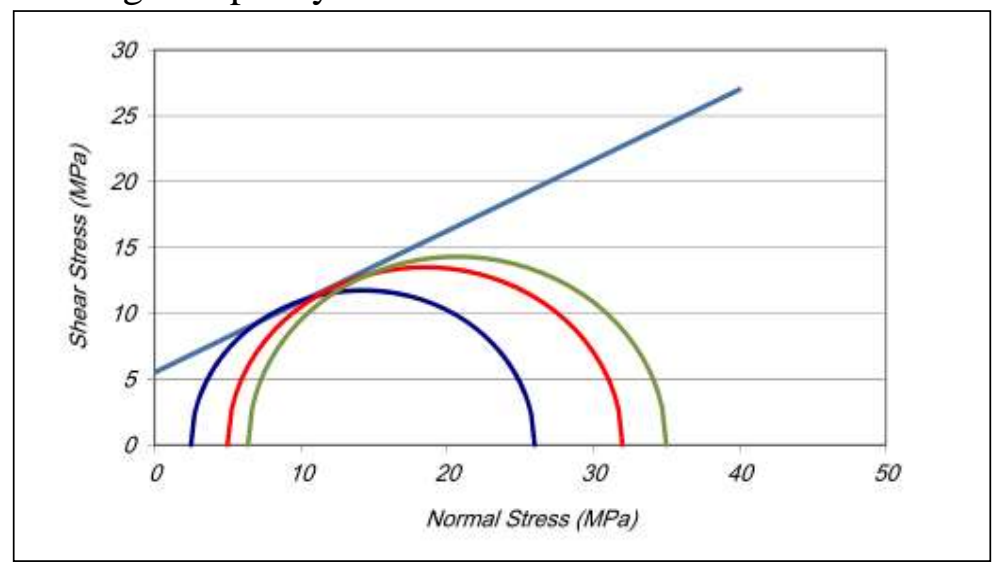

Figure 13. The Mohr's Circle for slurry with density of 92 PCF containing $0.3 \%$ wt. nanoparticles (prog. 2-2)

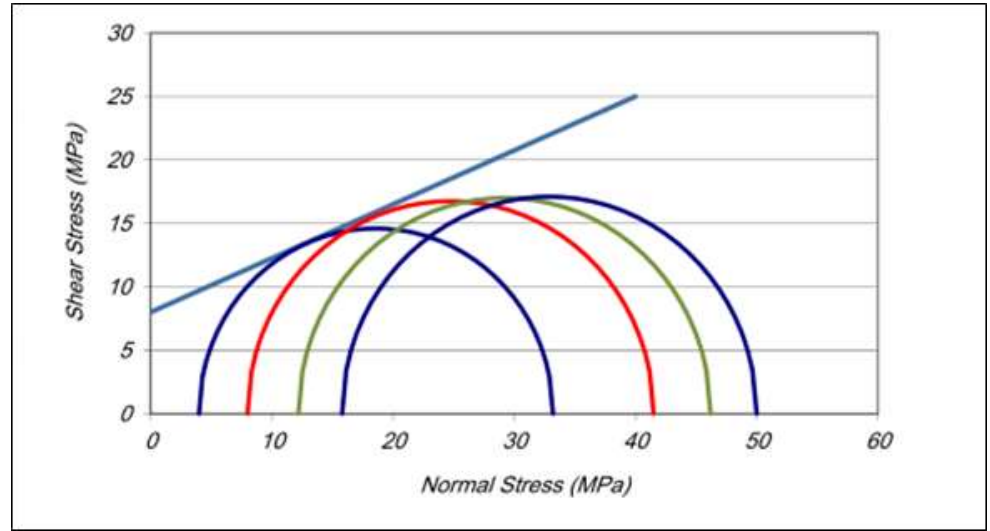

Figure 14. The Mohr's Circle for slurry with density of 92 PCF containing $0.3 \%$ wt nanoparticles without anti-gas migration additive (prog. 2-3) [33]

Table 9. Mechanical parameters obtained from Mohr's circles for slurry with density of 92 PCF

\begin{tabular}{cccc}
\hline & Program & $2-2$ & $2-3$ \\
92 PCF & Peak stress (MPa) & 50 & 35 \\
& C (MPa) & 5.5 & 8 \\
& & 28 & 23 \\
\hline
\end{tabular}

\section{Conclusion}

Enhancement of cement slurry physical and chemical properties including, rheology, free water, thickening time, gel strength, density, viscosity, and strength by adding nano-silica particles were observed. The gas migration was mitigated, as well. According to the experiment, the following are concluded.
- Addition of the nanoparticle improved the rheology of the cement slurry in both 88 and 82 PCF density and mentioned conditions.

- Nanoparticle has not changed the amount of free water and Fluid loss. So, it revealed no negative effect on these parameters. 
- Cement slurry thickening time remained constant in all the programs. So nanoparticle had no negative effect on the thickening time.

- Regarding the diagrams and data, the compressive strength as an important parameter in the cement slurry specification was increased by enhancing the amount of the nanoparticle, which is so favorable.

- In the case of SGSA test, transient time was decreased by increasing the amount of the nanoparticle. As all migration problems initiated in this critical time, it revealed that the nanoparticle had a positive effective on the gel strength of cement slurries.

- Nanoparticle had greatly reduced the rate of the gas migration in some defend conditions of cement slurries.

- In Mohr's circles, the peak stress and the cohesion parameter (C) in program 2-3 is much higher than the program 2-2. So, it can be concluded that, the nanoparticle not only did not reduce strength, but also increased it, especially at the absence of the antigas migration additive [34]. Bigger peak stress referred to a better result for cement slurry.

It should be recalled that, in this field of study, with especial attention on its vital effects on the industrial output, new windows can be opened with significant attendance on researches with various types of nano-materials (such as Nano hematite). Also, other situations can be studied such as: different components and concentrations in main slurries program, wells with high values of GOR or different liner dimensions (such as 5 inch liner), while it followed a great pattern in minimizing gas migration.

\section{Nomenclature}

\begin{tabular}{|cc|}
\hline BHST & Bottom Hole Static Temperature \\
BHCT & Bottom Hole Circulating \\
& Temperature \\
FMA & Fluid Migration Analyzer \\
\hline
\end{tabular}

\begin{tabular}{|cc|}
\hline PCF & $\begin{array}{c}\text { Pound per square feet(the most } \\
\text { common unit of density used in } \\
\end{array}$ \\
petroleum industry) \\
PV & Plastic viscosity \\
SGSA & Static gel strength analyzer \\
UCA & Ultrasonic Cement Analyzer \\
YP & Yield point \\
$\theta$ & Dial reading at viscometer \\
& (Rotational speed) \\
$\varphi$ & Friction angle \\
GOR & Gas Oil Ratio \\
FLC & Fluid Loss Controller \\
\hline
\end{tabular}

\section{Acknowledgements}

The work presented in this paper is part of a research project of Mahmoud Bayanak (Ph.D. student in science in chemical engineering, Department of Chemical Engineering, Mahshahr Branch, Islamic Azad University, Mahshahr, Iran).

\section{References}

[1] J. Plank, C. Tiemeyer, D. Buelichen, SPE Drill. Compl, 2013, 28, 398-404.

[2] Z. Xu, M. Zhang, F. Min, Integrated Ferroelectrics, 2011, 129, 160-168.

[3] S. Aydın, A. Aytaç, K. Ramyar, Constr. Build. Mater., 2009, 23, 24022408.

[4] V. Rahhal, V. Bonavetti, L. Trusilewicz, Build. Mater., 2012, 27, 8290.

[5] R. Wang, L. Yao, P. Wang, Constr. Build. Mater., 2013, 41, 538-544.

[6] J. Plank, Z. Dai, H. Keller, Cem. Concr. Res., 2010, 40, 45-57.

[7] X. Duan, S. Li, X. Jiang, J. Daqing Pet. Inst., 2011, 35, 79-83.

[8] H. Wang, W. Li, F. Sun, Appl. Mech. Mater., 2014, 744-746.

[9] J. Guo, X. Xia, S. Liu, Pet. Explor. Dev., 2013, 40, 656-660.

[10] X. Xia, J. Guo, S. Liu, Mater. Sci. Forum, 2015, 814, 191-198.

[11] M. Wang, R. Wang, S. Zheng, Cem. Concr. Res., 2015, 76, 62-69.

[12] G. Quercia, H. Brouwers, A. Garnier, A. Mater. Des., 2016, 96, 162170. 
[13] C. Sumit, P. Sarada, R. Aparna, Ind. Eng. Chem. Res., 2013, 52, 1252-1260.

[14] Q. Ren, H. Zou, M. Liang, RSC Adv., 2014, 4, 44018-44025.

[15] S. Bachu, S. International Journal of Greenhouse Gas Control, 2017, 61, $146-154$.

[16] G. Li, Cement and Concrete Research, 2004, 34, 1043-1049.

[17] B.H. Green, Proceedings of ACI session on Nanotechnology of concrete: Recent Developments and Future Perspectives, 2006, 119-130.

[18] K.L. Lin, W.C. Chang, D.F. Lin, H.L. Luo, M.C. Tsai, Journal of Environmental Management, 2008, 21, 708-714.

[19] E. Knapen, D. Van Gemert, Cem. Concr. Res, 2009, 39, 6-13.

[20] M. Wang, R. Wang, H. Yao, Constr. Build. Mater., 2016, 111, 710-718.

[21] J. Fernández, F. González, C. Pesquera, J. Therm. Anal. Calorim., 2016, 125, 703-710.

[22] H Zhang, J Zhuang, S Huang, S. RSC Adv., 2015, 5, 55428-55437.

[23] M. Nili, A. Ehsani, Mater. Des., 2015, 75, 174-183.

[24] R. Seright, A. Campbell, P. Mozley, SPE J., 2010, 15, 341-348.

[25] Y. Qing, Z. Zenan, K. Deyu, C. Rongshen, Construction and Building Materials, 2007, 21, 539-545.

[26] K.L. Lin, W.C. Chang, D.F. Lin, H.L. Luo, M.C. Tsai, Journal of
Environmental Management, 2008, 12, 708-714.

[27] J. Björnström, A. Martinelli, A. Matic, L. Borjesson, I. Panas, Chemical Physics Letters, 2004, 392, 242-248.

[28] A.R. Ismail, W.R. Wan Sulaiman, M.Z. Jaafar, I. Ismail, E. Sabu Hera, Materials Science Forum, 2016, 864, 189-193.

[29] M. Shah, A. Sircar, M. Mandlik, D. Vaidya, Asian Journal of Science and technology, 2017, 8, 5812-5816.

[30] S. Ridha, U. Yerikania, Journal of Civil Engineering Research, 2015, 5, 610.

[31] Z. Xu, M. Zhang, F. Min, Integrated Ferroelectrics, 2011, 129, 160-168.

[32] K. Abid, R. Gholami, H. Elochukwu, M. Mostofi, C. H. Bing, G. Muktadir, Petroleum, 2018, 4, 198-208. [33] R. Zhang, X. Cheng, P. Hou, Z. Ye, Construction and Building Materials 81, 2015, 1, 35-41.

[34] R. Sarade, N. Rajguru, M. Pawar, S. Shinde, R. Wayase, K. Zodge, R.B. Ghoghare, International Journal of Engineering Science and Computing, 2017, 7, 10780-10782.

H. Biricik, N. Sarier, Materials Research, 2014, 17, 570-582.

[35] K. Munawar, B. M. Jan, C. W. Tong, M. A. Berawi, Applied Energy, 2017, 191, 287-310.

How to cite this manuscript: Mahmoud Bayanak, Soroush Zarinabadi, Khalil Shahbazi, Alireza Azimi. Improvement in gas migration reduction in oil wells by using of nanoparticles: an experimental investigation. Eurasian Chemical Communications, 2020, 2(1), 13-26. 